\title{
DIRECTLY-COUPLED MICROSTRIP ARRAY ANTENNAS FOR WIDEBAND APPLICATION
}

\author{
Dinesh B Ganure $^{1}$, S L Mallikarjun ${ }^{2}$, P M Hadalgi ${ }^{3}$, P V Hunagund ${ }^{4}$ \\ ${ }^{1}$ Research Student, Department of Applied Electronics, Gulbarga University, Gulbarga, Karnataka, India. \\ ${ }^{2}$ Guest Faculty, Department of Applied Electronics, Gulbarga University, Gulbarga, Karnataka, India. \\ ${ }^{3}$ Professor, Department of Applied Electronics, Gulbarga University, Gulbarga, Karnataka, India \\ ${ }^{4}$ Professor, Department of Applied Electronics, Gulbarga University, Gulbarga, Karnataka, India
}

\begin{abstract}
A method for increasing the bandwidth of microstrip array antenna by adding additional resonator, which is directly - coupled to the non - radiating edges of a radiating element is narrated. The experimental result of four elements non-radiating edge directly coupled rectangular microstrip array antenna (FNCRMAA) shows wide band with bandwidth of $15.63 \%$. Further extending the elements of array to eight elements non-radiating edge directly - coupled rectangular microstrip array antenna (ENCRMAA), the antenna shows improved impedance bandwidth up to $20.76 \%$. The design specifications, radiation patterns and gain of the proposed antennas are shown and reported.
\end{abstract}

Keywords: Wide band, Non-radiating edge, direct-coupling, corporate feed, microstrip array.

\section{INTRODUCTION}

The modern communication system needs multifunction devices, where users can obtain multiple services with only one instrument. In addition, compact technology is commonly demanded for multi-band and wide-band applications. Microstrip patch antennas are broadly used because of their many advantages, such as the light weight, lower profile, and conformity. On the other hand, these antennas have a main drawback by its narrow operating bandwidth [1]. Researchers have made a lot of efforts to overcome this problem and various configurations have been presented to widen the bandwidth. Though, the bandwidth and the size of an antenna have generally mutual conflicting properties, that is, enhancement of one of the characteristics normally results in degradation of the other.

A new configuration has been proposed for wide band operation without increasing the effective area. The concept of direct-coupling is used for designing a single layer four elements array. Further, the study is extended for eight elements array and the obtained experimental results are presented and discussed.

\section{DESIGN SPECIFICATIONS}

A low cost glass epoxy substrate material is used to design the proposed antennas with the dielectric constant $\varepsilon r=4.2$ and thickness $\mathrm{h}=1.6 \mathrm{~mm}$. Fig. 1 shows the geometry of FNCRMAA.

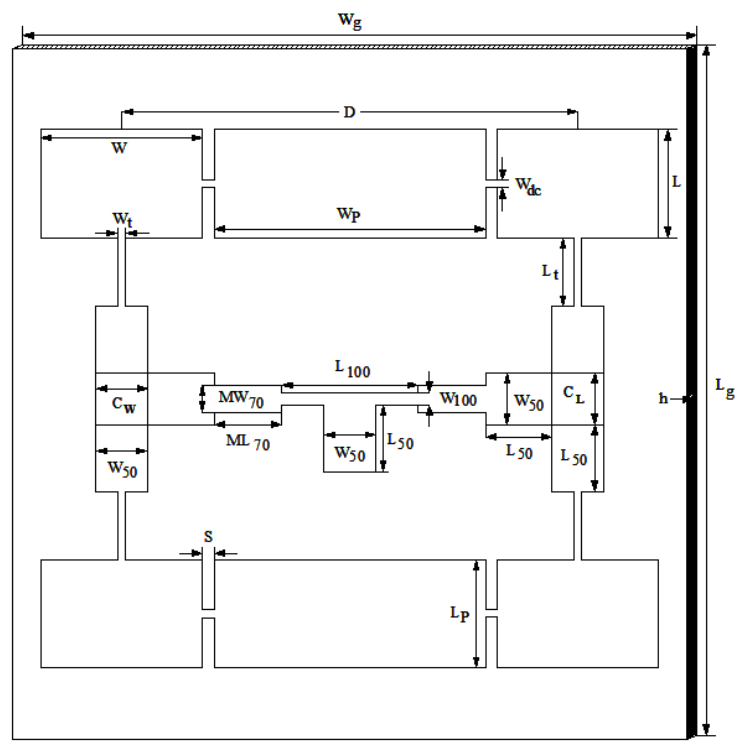

Fig-1: Geometry of FNCRMAA

Radiating patches of array are designed for the frequency of $9.4 \mathrm{GHz}$ with dimensions $\mathrm{L}=6.6 \mathrm{~mm}$ and $\mathrm{W}=9.9 \mathrm{~mm}$. While, for the proposed antenna the radiation pattern is measured with the help of bench and in bench it is observed that the microwave source i.e. Gunn oscillator starts to give more power from $9.4 \mathrm{GHz}$, hence we have taken $9.4 \mathrm{GHz}$ as the design frequency. An optimized non-radiating element of dimension of length, $\mathrm{LP}=6.6 \mathrm{~mm}$ and width, $\mathrm{WP}=17.2 \mathrm{~mm}$ is placed between the radiating elements, which forms the nonradiating edge which is direct-coupled. The distance between 
parasitic and the radiating element $\mathrm{S}$ is optimized and is taken as $0.025 \lambda \mathrm{g}$, where $\lambda \mathrm{g}$ is the operating wavelength in $\mathrm{mm}$ [2]. The direct coupling is done through a coupler with width Wdc $=0.4 \mathrm{~mm}$ and it is an optimised dimension. The length will be same as S. Length $\mathrm{Lg}=48.2 \mathrm{~mm}$ and width $\mathrm{Wg}=50.5 \mathrm{~mm}$ of ground plane of antenna is calculated using the equations; $\mathrm{Lg}=6 \mathrm{~h}+\mathrm{L}$ and $\mathrm{Wg}=6 \mathrm{~h}+\mathrm{W}$ [3]. The radiating array elements are excited through simple corporate feed arrangement. This feed arrangement consists of matching transformer, quarter wave transformer and coupler for better impedance matching between feed and radiating elements [4].

The two-way power divider of $100 \Omega$ of dimension $\mathrm{L} 100=8.3$, $\mathrm{W} 100=0.7 \mathrm{~mm}$ is used between impedances of $70 \Omega$ matching transformer of measurements ML70 $=4.1$, MW70 $=1.6 \mathrm{~mm}$ and $50 \Omega$ of dimension $\mathrm{L} 50=4.1, \mathrm{~W} 50=3.1 \mathrm{~mm}$. A link of dimension $\mathrm{CL}=\mathrm{CW}=3.1 \mathrm{~mm}$ is used between $50 \Omega$ microstrip lines to couple the power $[5,6]$. The $50 \Omega$ microstrip line is connected at the centre of the driven element through a quarter wave transformer of dimension $\mathrm{Lt}=4.1 \mathrm{~mm}$, $\mathrm{Wt}=0.4 \mathrm{~mm}$ for better impedance matching. To the $50 \Omega$ microstrip line feed, a coaxial SMA connector is connected for feeding the power. Elements of array are kept at a distance of $\mathrm{D}=27.9 \mathrm{~mm}$ from their centre point. This distance is chosen to attain minimum side lobes in the radiation pattern and to add the radiated power in free space [7]. Further, the study is carried out for ENCRMAA. Fig. 2 shows the geometry of ENCRMAA

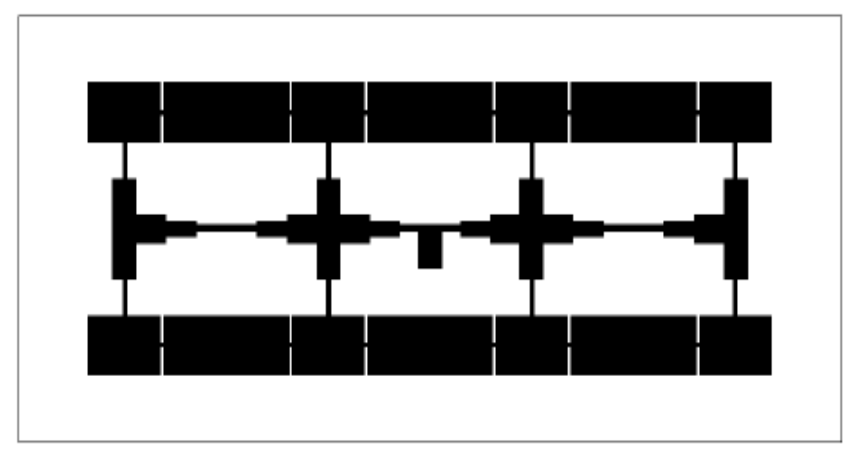

Fig-2: Geometry of ENCRMAA

\section{RESULT AND DISCUSSION}

Impedance bandwidths for the proposed antennas are measured. The measurements are taken on Vector Network Analyser. Graph of reflection coefficient vs. frequency of FNCRMAA and ENCRMAA are shown in Fig. 3.

From figure 3, it is observed that FNCRMAA offers wide band in the range 9.32 to $11.70 \mathrm{GHz}$, resonating at $11.08 \mathrm{GHz}$, with magnitude $1740 \mathrm{MHz}(15.63 \%)$. When compared to the single radiating element $(2.85 \%)$ the bandwidth is 5.48 times more than the proposed antenna. Although the patches are calculated for $9.4 \mathrm{GHz}$ frequency, the proposed antenna is resonating near to $11.08 \mathrm{GHz}$. This may be due to parasitic patch with longer width compared to the width of designed patch. The together resonance of each element with parasitic coupling results in the improvement of impedance bandwidth [2]. The minimum reflection coefficient is measured and is found to be $-26.40 \mathrm{~dB}$.

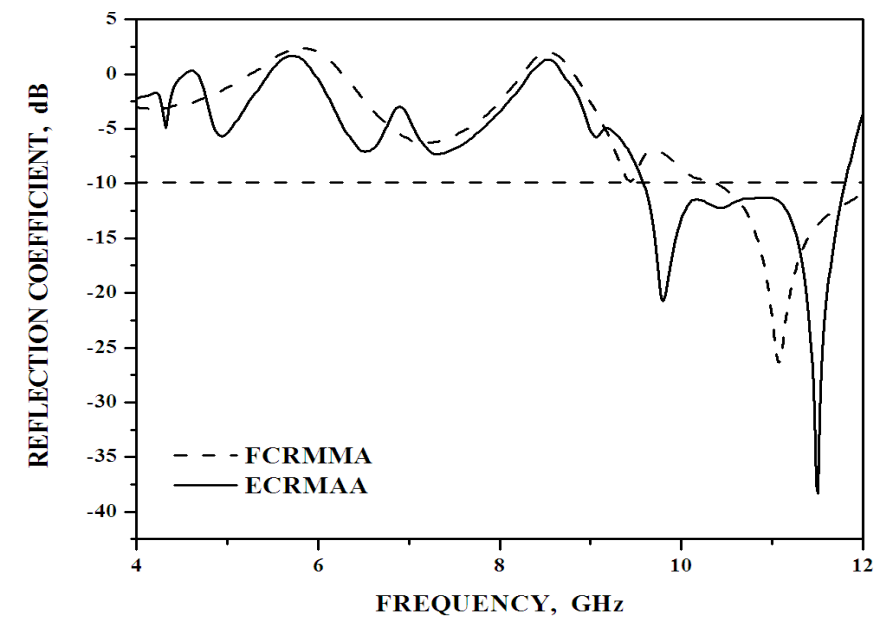

Fig-3: Graph of reflection coefficient versus frequency of FNCRMAA and ENCRMAA

Again, from the graph it is apparent that ENCRMAA is resonating for single wide band with a magnitude of $2220 \mathrm{MHz}$ $(20.76 \%)$. When compared with FNCRMAA the impedance bandwidth of ENCRMAA is 1.32 times more. The minimum reflection coefficient in this antenna is found to be $-38.34 \mathrm{~dB}$ at $11.50 \mathrm{GHz}$.

The H-plane co-polarization and cross-polarization radiation patterns of FNCRMAA and ENCRMAA are measured at resonating frequency with minimum return loss and are shown in Fig. 4 and 5. It is clear from these figures, that both the antennas are showing broad side radiation characteristics in nature with lower cross polarization level which are less than $-11 \mathrm{~dB}$ and $-16 \mathrm{~dB}$ for FNCRMAA and ENCRMAA respectively.

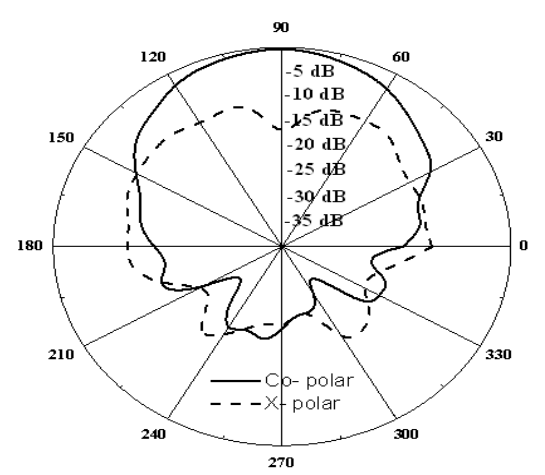

Fig-4: Radiation pattern of FNCRMAA at $11.08 \mathrm{GHz}$ 


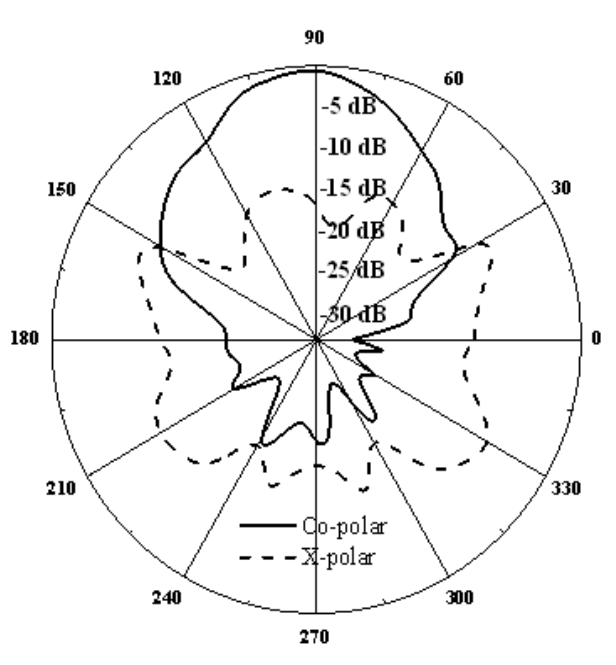

Fig-5: Radiation pattern of ENCRMAA at $11.50 \mathrm{GHz}$

HPBW's of FNCRMAA and ENCRMAA are calculated and are found to be $62^{\circ}$ and $39^{\circ}$ respectively. When compared to $[8,9]$, the HPBWs of the proposed antennas are improved.

The gain is measured, the power transmitted $\left(P_{t}\right)$ by the pyramidal horn antenna and the power received $\left(P_{s}\right)$ by FNCRMAA and ENCRMAA are calculated separately. With the help of obtained data, the gain of antenna under test $\left(G_{T}\right)$ in $\mathrm{dB}$ is calculated using the equation [9],

$$
\left(G_{T}\right)_{d B}=\left(G_{s}\right)_{d B}+10 \log \left(P_{t} / P_{s}\right)
$$

Where, $G s$ is the gain of standard pyramidal horn antenna. It is seen that the gain of FNCRMAA and ENCRMAA are $2.14 \mathrm{~dB}$ and $2.45 \mathrm{~dB}$ respectively. When compared with FNCRMAA, the gain of ENCRMAA is improved by 1:1.14 ratios. It is clear that by using array configuration and direct - coupling technique, the gain of the antenna also improves considerably [10].

\section{CONCLUSIONS}

The experimental study reveals that, the antennas are simple in fabrication and design as well as quite good in improving the impedance bandwidth and give better gain with good broadside radiation pattern at the resonating frequencies. The wide-band microstrip patch array antenna can provide an option to large bandwidth planar antennas, in applications in which large bandwidths are needed for operating at two separate transmitreceiver bands. Moreover, the antennas are also better as they use single layer low cost substrate material and find vast applications in modern communication system, microwave wireless communication system and in radar communication systems.

\section{ACKNOWLEDGEMENTS}

The authors want to acknowledge the Department of Science and Technology (DST), Govt. of India, New Delhi, for sanctioning Vector Network Analyzer under the FIST Programme.

\section{REFERENCES}

[1]. Fan Yang; Xue-Xia Zhang; Xiaoning Ye; and Yahya Rahmat-Samii, "Wide-Band E-Shaped Patch Antennas for Wireless Communications", IEEE Trans. Antennas Propog. Vol. 49, No. 7, 2001.

[2]. Girish Kumar; and K.P. Ray, "Broadband Microstrip Antennas", Artech House, London, pp. 89-110, 2003.

[3]. I. J. Bhal and P. Bhartia, "Microstrip Antennas", Artech House, New Delhi, pp. 230-234, 1980.

[4]. Kai Fong Lee; and Weichen, "Advances in Microstrip and Printed Antennas", John Wiley, New York, 1997.

[5]. I. I Jong Kim; and Y. Young Joong, "Design of wideband microstrip array antenna using the coupled lines", IEEE Antenna and Prop. Soci. Int. Symp. 3, pp. 1410-1413, 2000.

[6]. X. M. Oing; and Y. W. M Chia, "Circularly polarized circular ring slot antenna fed by stripline hybrid coupler", Elect. Lett. 35, 2154-2155, 1999.

[7]. Constantine Balanies A. "Antenna Theory Analysis and Design”, John Wiley \& Sons Inc. New York, 1982.

[8]. S. L. Mallikarjun, R. G. Madhuri, S. A. Malipatil and P. M. Hadalgi, "Development of microstrip array antennas for wide band and multi band applications", Indian Journal of Radio and Space Physics. 38, pp. 289-294, 2009.

[9]. P. M. Hadalgi; and S. L. Mallikarjun, "Design and development of microstrip array antenna with broader bandwidth and beam", International Journal of Electronics Engineering. 1, pp. 251-253, 2009

[10]. Sang-Hyuk Wi,; Yong-Shik Lee; and Jong-Gwan Yook, "Wideband microstrip patch antenna with U-shaped parasitic elements", IEEE Trans. Antennas Propog. 55, pp. 1196-1199, 2007 